\title{
Glucosamine/Chondroitin and Mortality in a US NHANES Cohort
}

Dana E. King, MD, MS and Jun Xiang, MS, MA

Background: Limited previous studies in the United Kingdom or a single US state have demonstrated an association between intake of glucosamine/chondroitin and mortality. This study sought to investigate the association between regular consumption of glucosamine/chondroitin and overall and cardiovascular (CVD) mortality in a national sample of US adults.

Methods: Combined data from 16,686 participants in National Health and Nutrition Examination Survey 1999 to 2010, merged with the 2015 Public-use Linked Mortality File. Cox proportional hazards models were conducted for both CVD and all-cause mortality.

Results: In the study sample, there were 658 (3.94\%) participants who had been taking glucosamine/ chondroitin for a year or longer. During followup (median, 107 months), there were 3366 total deaths (20.17\%); 674 (20.02\%) were due to CVD. Respondents taking glucosamine/chondroitin were less likely to have CVD mortality (hazard ratio [HR] $=0.51 ; 95 \% \mathrm{CI}, 0.28-0.92)$. After controlling for age, use was associated with a 39\% reduction in all-cause $(\mathrm{HR}=0.61 ; 95 \% \mathrm{CI}, 0.49-0.77)$ and $65 \%$ reduction $(\mathrm{HR}=0.35 ; 95 \%$ CI, 0.20-0.61) in CVD mortality. Multivariable-adjusted HR showed that the association was maintained after adjustment for age, sex, race, education, smoking status, and physical activity (all-cause mortality, HR = 0.73; 95\% CI, 0.57-0.93; CVD mortality, HR = 0.42; 95\% CI, 0.23-0.75).

Conclusions: Regular intake of glucosamine/chondroitin is associated with lower all-cause and CVD mortality in a national US cohort and the findings are consistent with previous studies in other populations. Prospective studies to confirm the link may be warranted. ( $\mathrm{J}$ Am Board Fam Med 2020;33:842-847.)

Keywords: Cardiovascular Diseases, Chondroitin, Cohort Studies, Glucosamine, Nutrition Surveys, Osteoarthritis, Proportional Hazards Models

\section{Introduction}

Glucosamine with chondroitin is a widely used combination supplement used to treat osteoarthritis and joint pain and it is available without a prescription in the United States. Both glucosamine and chondroitin are natural compounds found in cartilage, and can take as a dietary supplement to treat osteoarthritis and joint pain. ${ }^{1}$ Several large clinical trials have compared glucosamine/chondroitin to

This article was externally peer reviewed.

Submitted 24 May 2020; revised 29 May 2020; accepted 3 June 2020.

From the Department of Family Medicine, West Virginia University, Morgantown.

Funding: None.

Conflict of interest: None.

Author participation: DEK and JX participated in the research study and in preparation of this manuscript.

Corresponding author: Dana E. King, MD, MS, Department of Family Medicine, West Virginia University, University Town Centre, 6040 University Town Centre Drive, Morgantown, WV (E-mail: kingdana@wvumedicine.org). either placebo or celecoxib but have not demonstrated significant improvement in arthritis pain, although the glucosamine/chondroitin exhibited no long-term safety issues. ${ }^{2-5}$ However, 2 recent large cohort studies, 1 in the state of Washington and 1 in the United Kingdom, have found somewhat surprising beneficial effects on a different outcome, long-term mortality. ${ }^{6,7}$

In this study, we sought to investigate the association of daily use of glucosamine/chondroitin with cardiovascular and overall mortality in a large US cohort. We also wanted to be able to take into account demographic and disease variables that might influence the association.

\section{Materials and Methods \\ Study Population}

The National Health and Nutrition Examination Survey (NHANES) is a series nationally representative 
cross-sectional survey conducted by National Center for Health Statistics (NCHS). The purpose of the surveys was to assess the health and nutrition status among noninstitutionalized population in the United States using a complex, multistage probability design. Starting from 1999, the NHANES data are released on public-use data files in 2-year increments. Participants were interviewed at home followed by an examination in a mobile examination center for collection of various health and nutrition related data. Informed consents were obtained from all participants and the protocols for conducting the surveys were approved by the Center of Disease Control and Prevention Institutional Review Board. Details on survey design and response rate can be found on the NHANES Web site: NCHS. NHANES Survey methods and analytic guidelines. Available at: https://wwwn.cdc. gov/nchs/nhanes/analyticguidelines.aspx.

\section{Study Participants}

The present study used combined data from NHANES 1999 to 2010. We merged the baseline survey data with the 2015 Public-use Linked Mortality File, which provides mortality follow-up data from the date of survey participation through December 31, 2015. Information obtained from the mortality data included vital status, the number of person-months of followup from NHANES examination date and underlying leading cause of death, derived from the 10th revision of the International Statistical Classification of Diseases, Injuries, and Causes of Death (ICD-10) code (NCHS. Publicuse Linked Mortality File. Available at: https:// www.cdc.gov/nchs/data/datalinkage/public-use-2015linked-mortality-file-description.pdf.) Participants with missing vital status or cardiovascular disease (CVD) at baseline were excluded from the study.

\section{Mortality Outcomes}

The primary outcomes in this study were all-cause and cardiovascular mortalities. To identify all-cause mortality, we used mortality status variable, which coded " 0 " if assumed "alive" and " 1 " if assumed deceased. Cardiovascular mortality was identified using variable for leading cause of death. For NHANES 1999 to 2006, there were 9 specific categories from the underlying cause-of-death: heart disease, cancer, chronic lower respiratory disease, cerebrovascular diseases, diabetes, pneumonia and influenza, Alzheimer disease, kidney disease, and unintentional injuries. For NHANES 2007 to 2010, there were only 2 specific cause-of-death groups, heart disease and cancer, due to the short follow-up time and small sample sizes for the other cause-specific death categories. All other causes of death were residual. In this study, we defined death resulting from heart disease or cerebrovascular diseases as cardiovascular mortality. The follow-up time was calculated using person months from the mobile examination center date to date of death or the end of the mortality period (December 31, 2015).

\section{Glucosamine/Chondroitin Use}

The continuous NHANES has been collecting data on participants' use of dietary supplements. During the household interview using the ComputerAssisted Personal Interviewing system, participants were asked a series of questions related to use of dietary supplements for the past 30 days. For participants who indicated use of supplements in the past month, they were asked to list all supplements they had taken during this period; information on how long they have been taken and how much do they take daily were also collected for each supplement use. Each reported supplement was then linked to a dietary supplement database containing detailed ingredients information for each type of supplement. In this study, participants reporting use of glucosamine/chondroitin for 365 days or more before the interview date were identified as glucosamine/chondroitin users; participants reporting no use or use on fewer than 365 days were considered nonusers.

\section{Covariates}

Other demographic covariates extracted from the data included age, gender, race, Body Mass Index (BMI), smoking status, physical activity, and education. Participants were categorized into 4 age groups: 40 to 49 years, 50 to 59 years, 60 to 69 years, and 70 years or older. We combined 4 race categories of Non-Hispanic White, Non-Hispanic Black, Hispanic, and other race. BMI was classified as underweight $\left(<18.5 \mathrm{~kg} / \mathrm{m}^{2}\right)$, normal $\left(\geq 18.5 \mathrm{~kg} / \mathrm{m}^{2}\right.$ and $<25 \mathrm{~kg} /$ $\left.\mathrm{m}^{2}\right)$, overweight $\left(\geq 25 \mathrm{~kg} / \mathrm{m}^{2}\right.$ and $\left.<30 \mathrm{~kg} / \mathrm{m}^{2}\right)$, and obese $\left(\geq 30 \mathrm{~kg} / \mathrm{m}^{2}\right)$ based on the Center for Disease Control and Prevention breakdown. Smoking status was identified as current smoker and nonsmoker. We divided education into 2 levels of " $\leq 11$ years" and " $>11$ years." Physical activity was defined as " $\geq 150$ minutes" or " $<150$ minutes" of 
moderate-intense recreational physical activity per week.

\section{Statistical Analysis}

All analyses in this study were conducted using SAS (version 9.4, 2013, SAS Institute Inc. Cary, NC). Accounting for the complex survey design (including oversampling, survey nonresponse, and post stratification), we used appropriate sampling weights and SAS survey analysis procedures following NHANES survey methods and analytic guidelines.

Demographic characteristics of the study sample were compared between glucosamine/chondroitin users and nonusers using $\chi^{2}$ test. To estimate the association of glucosamine/chondroitin use with total mortality and cardiovascular mortality, Cox proportional hazards regression analysis was conducted; we analyzed unadjusted, age-adjusted, and multivariable-adjusted hazard ratio (HR). In the multivariable-adjusted model, age, gender, race, smoking status, education, and physical activity were included as covariates. All tests were 2 tailed, and $P<.05$ was considered statistical significance.

\section{Results}

Based on the inclusion criteria, a total of 16,686 participants were included in the study sample. Among the study sample, there were 658 (3.94\%) participants who had been taking glucosamine/ chondroitin for a year or longer. During followup (median, 107 months), there were 3366 total deaths (20.17\%), 674 (20.02\%) due to cardiovascular disease.

The $\mathrm{c}^{2}$ analysis results presented in Table 1 show that respondents who were taking glucosamine/chondroitin were more likely to be older, white, having a high school or higher education, not smoking, and exercising more.

Table 2 displays the results of the unadjusted, age-adjusted, and multivariable-adjusted associations between use of glucosamine/chondroitin and all-cause mortality and cardiovascular mortality. The unadjusted Kaplan-Meier survival curve for cardiovascular mortality in all participants is shown in Figure 1. Compared with nonusers, respondents taking glucosamine/chondroitin were about $49 \%$ less likely to experience cardiovascular mortality (HR $=0.51$; 95\% CI, 0.28-0.92). While controlling for age, glucosamine/chondroitin use was associated with a $39 \%$ reduction $(\mathrm{HR}=0.61 ; 95 \%$ CI, 0.49 $0.77)$ and $65 \%$ reduction $(\mathrm{HR}=0.35 ; 95 \% \mathrm{CI}$,
$0.20-0.61)$ in all-cause and cardiovascular mortality respectively. Multivariable-adjusted HR showed that the association was maintained after adjustment for age, gender, race, education, smoking status, and physical activity (all-cause mortality, $\mathrm{HR}=0.73 ; 95 \%$ CI, 0.57-0.93); cardiovascular mortality, $\mathrm{HR}=0.42$; 95\% CI, 0.23-0.75).

\section{Discussion}

The current study supports a strong association between regular intake of glucosamine/chondroitin and subsequent overall and cardiovascular mortality that was maintained after adjustment for factors likely to confound the association. These results are consistent with 2 recent large epidemiologic studies in the state of Washington and in the United Kingdom, and point to the need for long-term prospective studies.

The epidemiology study by Ma and colleagues ${ }^{6}$ used the UK Biobank to analyze mortality in regular users of glucosamine and found after adjustment a significantly lower risk of total cardiovascular (CVD) events ( $\mathrm{HR}=0.85 ; 95 \%$ CI, 0.80-0.90), CVD death $(\mathrm{HR}=0.78 ; 95 \% \mathrm{CI}, 0.70-0.87)$, coronary heart disease $(\mathrm{HR}=0.82 ; 95 \% \mathrm{CI}, 0.76-0.88)$, and stroke (HR $=0.91 ; 95 \% \mathrm{CI}, 0.83-1.00)$. The other study by Bell and colleagues ${ }^{7}$ investigated mortality in 77,510 residents of Washington State aged 50 to 76 years from 2000 to 2008 and also found lower likelihood of morality after adjustment for possible confounders; glucosamine (with or without chondroitin) had an HR of 0.82 (95\% CI, $0.75-0.90$,$) and chondroitin had an HR of 0.86$ (95\% CI, 0.78-0.96).

Inflammation and cytokine effects have been suggested as one of the possible mechanisms for the effects of glucosamine and chondroitin on mortality. In a double-blind randomized, crossover study in adult men and women, Navarro and colleagues ${ }^{8}$ found that serum C-reactive protein (CRP) concentrations were $23 \%$ lower after glucosamine and chondroitin compared with placebo $(P=.048)$. In the proteomics analyses in the same study, several pathways were significantly different between the interventions after Bonferroni correction, the most significant being a reduction in the "cytokine activity" pathway. ${ }^{8}$ Other investigations have found an association between suppression of certain phosphorylation pathways and the anticancer effect of glucosamine. ${ }^{9}$ Still other studies have found that glucosamine can 
Table 1. Demographical Characteristics of 40 Years or Older NHANES 1999-2010 Participants by Glucosamine/ Chondroitin Use of 1 Year or Longer $(n=16,686)$

\begin{tabular}{|c|c|c|c|}
\hline Characteristics & $\begin{array}{l}\text { Glucosamine/Chondroitin User } \\
(\mathrm{n}=658), \%(95 \% \mathrm{CI})\end{array}$ & $\begin{array}{c}\text { Glucosamine/Chondroitin } \\
\text { Nonuser }(\mathrm{n}=16,028), \% \\
(95 \% \mathrm{CI})\end{array}$ & $P$-Value* \\
\hline \multicolumn{4}{|l|}{ Age (years) } \\
\hline 40 to 49 & $16.7(12.0$ to 21.3$)$ & $38.2(36.6$ to 39.7$)$ & \multirow[t]{4}{*}{$<.0001^{\dagger}$} \\
\hline 50 to 59 & $29.6(24.9$ to 34.3$)$ & $28.9(27.7$ to 30.0$)$ & \\
\hline 60 to 69 & $29.3(24.7$ to 33.9$)$ & $17.2(16.5$ to 18.0$)$ & \\
\hline$\geq 70$ & $24.5(21.4$ to 27.6$)$ & 15.7 (14.9 to 16.6$)$ & \\
\hline \multicolumn{4}{|l|}{ Sex } \\
\hline Male & $42.7(38.5$ to 46.9$)$ & 46.1 (45.2 to 46.9$)$ & \multirow[t]{2}{*}{.13} \\
\hline Female & $57.3(53.1$ to 61.5$)$ & $53.9(53.1$ to 54.8$)$ & \\
\hline \multicolumn{4}{|l|}{ Race } \\
\hline Non-Hispanic White & $90.8(88.3$ to 93.3$)$ & $74.8(72.3$ to 77.2$)$ & \multirow[t]{4}{*}{$<.0001^{\dagger}$} \\
\hline Non-Hispanic Black & $2.1(1.3-3.1)$ & $10.4(9.0$ to 11.8$)$ & \\
\hline Hispanic & $3.2(1.9-4.4)$ & $10.1(8.3$ to 11.9$)$ & \\
\hline Other & $3.8(1.8-5.8)$ & $4.7(4.0$ to 5.3$)$ & \\
\hline \multicolumn{4}{|l|}{ Body mass index } \\
\hline Underweight $\left(<18.5 \mathrm{~kg} / \mathrm{m}^{2}\right)$ & $1.4(0.03-2.8)$ & $1.4(1.2-1.7)$ & \multirow[t]{4}{*}{.93} \\
\hline Normal $\left(18.5\right.$ to $\left.24.9 \mathrm{~kg} / \mathrm{m}^{2}\right)$ & $26.9(22.4$ to 31.5$)$ & $27.7(26.5$ to 28.8$)$ & \\
\hline Overweight $\left(25-29.9 \mathrm{~kg} / \mathrm{m}^{2}\right)$ & $37.8(33.3$ to 42.3$)$ & 36.1 (35.0 to 37.2$)$ & \\
\hline Obese $\left(\geq 30 \mathrm{~kg} / \mathrm{m}^{2}\right)$ & $33.8(29.2$ to 38.4$)$ & $34.8(33.6$ to 36.0$)$ & \\
\hline \multicolumn{4}{|l|}{ Education } \\
\hline$\geq$ high school & 92.1 (89.6 to 94.6$)$ & $80.3(79.1$ to 81.5$)$ & \multirow[t]{2}{*}{$<.0001^{\dagger}$} \\
\hline$<$ high school & $7.9(5.4$ to 10.4$)$ & 19.7 (18.5 to 20.9$)$ & \\
\hline \multicolumn{4}{|l|}{ Smoking } \\
\hline Current smoker & $6.2(3.4$ to 9.0$)$ & $20.3(19.2$ to 21.4$)$ & \multirow[t]{2}{*}{$<.0001^{\dagger}$} \\
\hline Non-smoker & 93.8 (91.0 to 96.6$)$ & 79.7 (78.6 to 80.8$)$ & \\
\hline \multicolumn{4}{|l|}{ Physical activity } \\
\hline$\geq 150$ minutes/week & $59.0(54.1$ to 63.8$)$ & $44.5(42.7$ to 46.3$)$ & \multirow[t]{2}{*}{$<.0001^{\dagger}$} \\
\hline$<150$ minutes/week & $41.0(36.2$ to 45.9$)$ & $55.5(53.7$ to 57.3$)$ & \\
\hline
\end{tabular}

${ }^{*} P$-value was estimated from $\chi^{2}$ analysis.

${ }^{\dagger} P<.001$.

CI, confidence interval; NHANES, The National Health and Nutrition Examination Survey.

reduce kidney injury in rats through attenuation of oxidative stress. ${ }^{10}$ Glucosamine has also been found to influence Low density lipoprotein cholesterol (LDL) size and binding capacity in a study of aortic smooth muscle, a mechanism that could potentially reduce the development of atherosclerosis and subsequent cardiovascular disease. ${ }^{11}$

Could the association observed between glucosamine/chondroitin intake and mortality be due to another factor? Yes, but this is made less likely by the consistent direction of the findings in diverse population settings in the United States and the United Kingdom. In all studies, the relationship was controlled for factors that might account for the relationship, including demographic and lifestyle factors such as exercise. Other possibilities include that otherwise-healthy people take supplements, and therefore live longer. Controlling for age, race, sex, education, and exercise can partially but perhaps not completely take the "healthy people" factor into account.

Limitations include that this is a cohort study and not a randomized trial; thus, the individuals taking glucosamine/chondroitin were self selected and not randomized, introducing possible bias. Further, the amount and consistency of supplement intake was not tracked for adherence throughout the follow-up period. We attempted to mitigate this impact by choosing only people who had been taking the supplement for a year or more, to select consistent long-term users, and in the current study, we ended up with a lower proportion of users 
Table 2. Unadjusted and Adjusted Hazard Ratio for All Causes of Mortality and Cardiovascular Mortality ( $\mathrm{n}=$ 16,686)

\begin{tabular}{|c|c|c|c|c|}
\hline \multirow[b]{2}{*}{ Models } & \multicolumn{2}{|c|}{ All-Cause Mortality $(\mathrm{n}=3366)$} & \multicolumn{2}{|c|}{ CVD Mortality $(n=674)$} \\
\hline & $\operatorname{HR}(95 \% \mathrm{CI})$ & $P$-Value* & HR $(95 \% \mathrm{CI})$ & $P$-Value* \\
\hline \multicolumn{5}{|l|}{ Unadjusted } \\
\hline \multicolumn{5}{|l|}{ Glucosamine/chondroitin } \\
\hline User & $0.88(0.70$ to 1.11$)$ & .27 & $0.51(0.28$ to 0.92$)$ & $.03^{\dagger}$ \\
\hline Non-user & - & & - & \\
\hline \multicolumn{5}{|l|}{ Age adjusted } \\
\hline \multicolumn{5}{|l|}{ Glucosamine/chondroitin } \\
\hline User & $0.61(0.49$ to 0.77$)$ & $<.0001^{\S}$ & $0.35(0.20$ to 0.61$)$ & $.0004^{\S}$ \\
\hline Non-user & - & & - & \\
\hline \multicolumn{5}{|l|}{ Age, years } \\
\hline 40 to 49 & - & & - & \\
\hline 50 to 59 & $1.96(1.55$ to 2.48$)$ & $<.0001^{\S}$ & $1.80(1.02$ to 3.15$)$ & $.04^{\dagger}$ \\
\hline 60 to 69 & $4.38(3.73$ to 5.15$)$ & $<.0001^{\S}$ & $4.98(2.98$ to 8.32$)$ & $<.0001^{\S}$ \\
\hline $70+$ & $15.29(13.18$ to 17.74$)$ & $<.0001^{\S}$ & 17.55 (11.54 to 26.69$)$ & $<.0001^{\S}$ \\
\hline \multicolumn{5}{|l|}{ Multivariable adjusted } \\
\hline \multicolumn{5}{|l|}{ Glucosamine/chondroitin } \\
\hline User & $0.73(0.57$ to 0.93$)$ & $.01^{\dagger}$ & $0.42(0.23$ to 0.75$)$ & $.004^{\ddagger}$ \\
\hline Non-user & - & & - & \\
\hline \multicolumn{5}{|l|}{ Age, years } \\
\hline 40 to 49 & - & & - & \\
\hline 50 to 59 & $2.01(1.60$ to 2.53$)$ & $<.0001^{\S}$ & $1.90(1.12$ to 3.24$)$ & $.02^{\dagger}$ \\
\hline 60 to 69 & $4.71(4.03$ to 5.50$)$ & $<.0001^{\S}$ & $5.49(3.37$ to 8.96$)$ & $<.0001^{\S}$ \\
\hline $70+$ & $17.53(15.18$ to 20.25$)$ & $<.0001^{\S}$ & 20.57 (13.97 to 30.29$)$ & $<.0001^{\S}$ \\
\hline \multicolumn{5}{|l|}{ Sex } \\
\hline Male & - & & - & \\
\hline Female & $0.69(0.63$ to 0.75$)$ & $<.0001^{\S}$ & $0.51(0.42$ to 0.60$)$ & $<.0001^{\S}$ \\
\hline \multicolumn{5}{|l|}{ Race } \\
\hline Non-Hispanic White & - & & - & \\
\hline Non-Hispanic Black & $1.15(1.03$ to 1.29$)$ & $.01^{\dagger}$ & $1.27(1.0$ to 1.60$)$ & $.04^{\dagger}$ \\
\hline Hispanic & $0.87(0.74$ to 1.02$)$ & .08 & $0.88(0.60$ to 1.28$)$ & .49 \\
\hline Other & 0.84 (0.62 to 1.12$)$ & .23 & $0.94(0.43$ to 2.04$)$ & .87 \\
\hline \multicolumn{5}{|l|}{ Education } \\
\hline$\geq$ High school & - & & - & \\
\hline$<$ High school & $1.30(1.17$ to 1.45$)$ & $<.0001^{\S}$ & & $.007^{\ddagger}$ \\
\hline \multicolumn{5}{|l|}{ Smoking status } \\
\hline Current smoker & 1.98 (1.78 to 2.20$)$ & $<.0001^{\S}$ & $1.61(1.23$ to 2.10$)$ & $.0007^{\S}$ \\
\hline Non-smoker & - & & - & \\
\hline \multicolumn{5}{|l|}{ Physical activity } \\
\hline$\geq 150$ minutes/week & $0.64(0.59$ to 0.70$)$ & $<.0001^{\S}$ & $0.58(0.46$ to 0.73$)$ & $<.0001^{\S}$ \\
\hline$<150$ minutes/week & - & & - & \\
\hline
\end{tabular}

CVD, cardiovascular disease; HR, hazard ratio; CI, confidence interval.

${ }^{*} P$-value was estimated from Cox proportional hazards models. ${ }^{\dagger} P<.05,{ }^{\ddagger} P<.01,{ }^{\S} P<.001$.

than in the UK study. In addition, people could have been taking other supplements that could have accounted for some of the findings, but there are too many supplements to control for all them. In addition, the survey is by self-report survey by the respondent for all questions including regarding whether they had other medical conditions. Finally, another possible limitation is that the respondents are mostly non-Hispanic whites, however, we controlled for race in the analyses. 
Figure 1. Probability of survival from cardiovascular mortality in 40 years or older NHANES 1999 to 2010 participants.

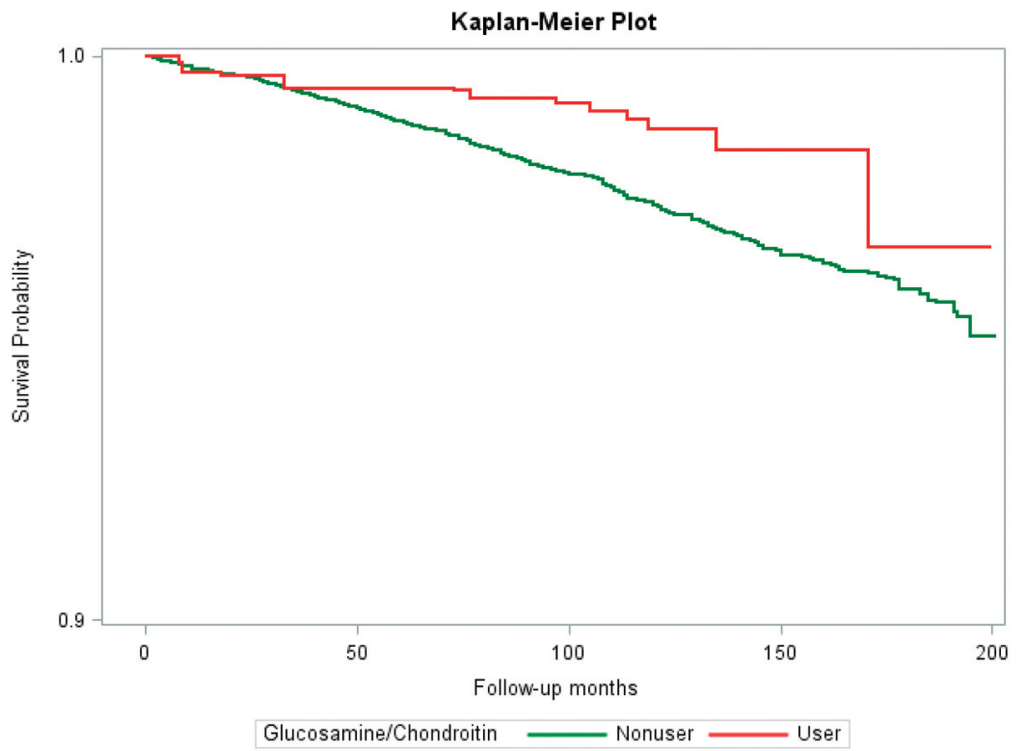

\section{Conclusion}

In conclusion, regular consumption of glucosamine/ chondroitin seems to be significantly associated with lower overall and cardiovascular mortality. Given the strength of the association, a $27 \%$ lower likelihood of overall mortality and a $58 \%$ lower likelihood of cardiovascular death, prospective studies may be warranted.

To see this article online, please go to: http://jabfm.org/content/ 33/6/842.full.

\section{References}

1. National Institutes of Health, National Center for Complementary and Integrative Health. Glucosamine and Chondroitin for Osteoarthritis. September 2017. Available at: https://nccih.nih. gov/health/glucosaminechondroitin\#hed1. Accessed March 16, 2020.

2. Wilkens P, Scheel IB, Grundnes O, Hellum C, Storheim K. Effect of glucosamine on pain-related disability in patients with chronic low back pain and degenerative lumbar osteoarthritis: a randomized controlled trial. JAMA 2010;304:45-52.

3. Sawitzke AD, Shi H, Finco MF, Dunlop DD, Bingham CO, 3rd, Harris CL, et al. The effect of glucosamine and/or chondroitin sulfate on the progression of knee osteoarthritis: a report from the glucosamine/chondroitin arthritis intervention trial. Arthritis Rheum 2008;58:3183-91.

4. Sawitzke AD, Shi H, Finco MF, Dunlop DD, Harris CL, Singer NG, et al. Clinical efficacy and safety of glucosamine, chondroitin sulphate, their combination, celecoxib or placebo taken to treat osteoarthritis of the knee: 2-year results from GAIT. Ann Rheum Dis 2010;69:1459-64.

5. Reginster JY, Deroisy R, Rovati LC, Lee RL, Lejeune E, Bruyere O, et al. Long-term effects of glucosamine sulphate on osteoarthritis progression: a randomised, placebo-controlled clinical trial. Lancet 2001;357:251-6.

6. Ma H, Li X, Sun D, Zhou T, Ley SH, Gustat J, et al. Association of habitual glucosamine use with risk of cardiovascular disease: prospective study in UK Biobank. BMJ 2019;365:11628.

7. Bell GA, Kantor ED, Lampe JW, Shen DD, White E. Use of glucosamine and chondroitin in relation to mortality. Eur J Epidemiol 2012; 27:593-603.

8. Navarro SL, White E, Kantor ED, Zhang Y, Rho J, Song $\mathrm{X}$, et al. Randomized trial of glucosamine chondroitin supplementation on inflammation and oxidative stress biomarkers and plasma proteomics profiles in healthy humans. PLoS One 2015;10: e0117534.

9. Yu Z, Ju Y, Liu H. Anti-lung cancer effect of glucosamine by suppressing the phosphorylation of FOXO. Mol Med Rep 2017;16:3395-400.

10. Hu J, Chen H, Jia P, Fang Y, Liu T, Song N, et al. Augmented O-GlcNAc signaling via glucosamine attenuates oxidative stress and apoptosis following contrast-induced acute kidney injury in rats. Free Radic Biol Med 2017;103:121-32.

11. Tannock LR, Little PJ, Wight TN, Chait A. Arterial smooth muscle cell proteoglycans synthesized in the presence of glucosamine demonstrate reduced binding to LDL. J Lipid Res 2002;43:149-57. 